\title{
Association between Serum Creatinine and Periodontal Disease Severity-A Comparative Clinicobiochemical Study
}

\author{
Aravindraaj Velayutham ${ }^{1}$, Jananni Muthu ${ }^{2}$, Pratebha Balư ${ }^{3}$, Saravanakumar Ravindran ${ }^{4}$
}

\begin{abstract}
Objectives: Periodontitis is a chronic inflammatory disease of the periodontium that produces adverse systemic effects including diabetes mellitus, adverse pregnancy outcomes, respiratory illness, etc. Based on new studies, chronic inflammation is speculated as a risk factor for impairment of kidney function. Periodontitis, as long time inflammation is posed as one of the nontraditional risk factors for end-stage renal diseases. Literature search reveals contradicting evidence on the influence of periodontal infection and inflammation on the renal function. In lieu of the above, this study aims in estimating and comparing the serum creatinine (SCR) levels with periodontal disease status in systemically healthy subjects.

Materials and methods: A total of 45 systemically healthy patients were recruited, and based on their periodontal status, they were divided into two groups: Group I ( $n=22)$ — subjects with periodontitis and Group II $(n=23)$-periodontally healthy subjects. Group I was again categorized into mild (CAL 1-2 mm), moderate (CAL 2-4 mm), and severe (CAL $\geq 5 \mathrm{~mm}$ ) based on the severity of the periodontal disease. After assessing the clinical parameters, blood was collected for SCR estimation. The comparison between PPD, CAL, and SCR was done using the paired $t$-test. The comparison of SCR levels with severity of the periodontitis (CAL) was done using ANOVA. All the statistical analyzes were performed using SPSS 17 software.

Results: The SCR value in Group I was $1.06 \pm 0.13$ and in Group II, $1.17 \pm 0.16$. Using the paired $t$-test to compare the creatinine values revealed that the difference between the two groups was statistically significant $(p=0.00001)$. By comparing the SCR levels with the severity of the periodontal disease, the mean value for mild periodontitis cases was $1.1 \pm 0.12$; for moderate periodontitis cases, $1.09 \pm 0.25$; and for severe periodontitis cases, $1.14 \pm 0.14$. ANOVA test values between the groups showed a statistical significance $(p<0.01)$.

Conclusion: The results from this study showed an inverse relationship between SCR levels and periodontitis. The causal relationship between periodontitis and low SCR could not be established. This inverse relationship might confound the analysis of the link between renal function and periodontal disease. From the results of this study, we conclude that considering other indices such as cystatin C and creatinine clearance is preferable, to explore the association between renal function and periodontal disease.

Keywords: Association, Periodontitis, Renal diseases, Serum creatinine.

Journal of Scientific Dentistry (2020): 10.5005/jp-journals-10083-0929
\end{abstract}

\section{INTRODUCTION}

Periodontitis by definition is the infectious disease resulting in inflammation within the tissues supporting the teeth, progressive loss of attachment, and bone loss. ${ }^{1}$ The link between periodontal disease and other systemic diseases has been extensively explored in the past two decades, leading to the emergence of a new branch of periodontology, the periodontal medicine. Periodontal infections have been found to adversely affect systemic health such as diabetes mellitus, preeclampsia atherosclerotic vascular disease, and metabolic syndrome. ${ }^{2-6}$

The common risk factors for renal dysfunction are diabetic mellitus, hypertension, and atherosclerosis diseases. Recently, systemic chronic inflammation has been speculated as risk factor for impairment of kidney function. Periodontitis, being a long-term inflammatory condition, can pose as one of the nontraditional risk factors. Serum creatinine (SCR) is considered as an indicator for renal function. ${ }^{7}$ Serum creatinine levels and glomerular filtration rates (GFRs) are the widely used indicators of renal function. ${ }^{8}$

Studies on the subjects with chronic renal failure revealed increased PPD, CAL as compared to healthy groups. ${ }^{9}$ Increased levels of antibodies against $P$. gingivalis were detected in the serum of subjects undergoing dialysis with severe periodontitis. ${ }^{10}$ The studies also demonstrate that patients with untreated periodontal
${ }^{1-4}$ Department of Periodontology, Indira Gandhi Institute of Dental Sciences, Sri Balaji Vidyapeeth, Puducherry, India

Corresponding Author: Jananni Muthu, Department of Periodontology, Indira Gandhi Institute of Dental Sciences, Sri Balaji Vidyapeeth, Puducherry, India, Phone: +91 9842455402, e-mail: jannpearl@gmail. com

How to cite this article: Velayutham A, Muthu J, Balu P, Ravindran S. Association between Serum Creatinine and Periodontal Disease Severity-A Comparative Clinicobiochemical Study. J Sci Den 2020;10(1):3-6.

Source of support: Nil

Conflict of interest: None

diseases have increased risk to have lower glomerular filtrate rate and subsequently elevated SCR concentrations. ${ }^{11}$ On the contrary, a study in Japanese men showed an inverse association between periodontal disease and normal SCR concentrations.

\section{Aıм}

The aim of the study was to estimate and compare the SCR levels with periodontal disease status in systemically healthy subjects.

(0) The Author(s). 2020 Open Access This article is distributed under the terms of the Creative Commons Attribution 4.0 International License (https://creativecommons. org/licenses/by-nc/4.0/), which permits unrestricted use, distribution, and non-commercial reproduction in any medium, provided you give appropriate credit to the original author(s) and the source, provide a link to the Creative Commons license, and indicate if changes were made. The Creative Commons Public Domain Dedication waiver (http://creativecommons.org/publicdomain/zero/1.0/) applies to the data made available in this article, unless otherwise stated. 


\section{Materials and Methods}

The study population was recruited from the patient pool reporting to Dept. of Periodontology of Indira Gandhi Institute of Dental Sciences, Sri Balaji Vidyapeeth, Puducherry. Reported nonsmokers and systemically healthy subjects of 20-60 years of age and with at least 20 natural teeth remaining were included initially. Subjects who were on or require antibiotic treatment during the course of study, women on hormonal contraceptives, pregnant and lactating women, smokers, subjects on steroids or NSAID in the past 3 months, subjects who have undergone any periodontal therapy in the past 6 months were excluded from the study.

For all the subjects initially recruited, body mass index (BMI), systolic and diastolic blood pressure, and serum glucose (PP) were analyzed. Patients with blood pressure variables $>130 / 90, \mathrm{BMI}>25.0$, and postprandial glucose levels $>140 \mathrm{mg} / \mathrm{dL}$ were excluded. Thus, a total of 45 subjects were finally selected for the study.

For the study subjects, the following periodontal parameters were recorded: probing pocket depth (PPD) and clinical attachment level (CAL). Based on the periodontal finding, the subjects were divided into two groups: Group I $(n=22)$ - subjects with periodontitis and Group II $(n=23)$ - periodontally healthy subjects.

Chronic periodontitis cases were defined as those having 5 or more teeth with $\mathrm{PD} \geq 5 \mathrm{~mm}$ and clinical attachment loss (CAL) $>2 \mathrm{~mm}$. Healthy controls were subjected with no probing depth (PD) greater than $4 \mathrm{~mm}$ and $C A L>1 \mathrm{~mm}$. Periodontitis was again categorized as mild (CAL 1-2 mm), moderate (CAL 2-4 mm), and severe ( $C A L \geq 5 \mathrm{~mm})$.

Serum sample collection: No special preparation of the patient was required prior to specimen collection. No special additives or preservatives were required. After assessing the clinical parameters, blood was collected for SCR estimation. The blood samples were collected under all aspects of precautions by vein puncture in antecubital vein. The area was cleaned and made aseptic by using a disinfectant solution and dried. 2 cc of venous blood was withdrawn with the help of a $2-\mathrm{mL}$ disposable syringe and a 24-gauge disposable needle. The sample was then distended into a plain test tube.

The collected blood was analyzed for SCR using commercially available kit that uses modified Jaffe's kinetic method for estimation (Creatinine Kit, Tulip Laboratories, Tulip Group, Verna, Goa, India).

Statistics: The comparison between PPD, CAL, and SCR was done using the paired $t$-test. The comparison of SCR levels with severity of the periodontitis (CAL) was done using ANOVA. All the statistical analyzes were performed using SPSS 17 software.

\section{Results}

Comparative analysis of periodontal parameters and SCR levels between the groups shows that the mean PPD in Group I was 5.19 \pm 0.53 and in Group II was $1.81 \pm 0.26$. The mean CAL in Group I was $5.51 \pm 0.53$ and in Group II was $1.81 \pm 0.26$.

The SCR value in Group I was $1.06 \pm 0.13$ and in Group II was 1.17 \pm 0.16 . The paired $t$-test to compare the creatinine values revealed that the difference between the two groups were statistically significant ( $p=0.00001$ ) (Table 1). By comparing the SCR levels with the severity of the periodontal disease, the mean value for mild periodontitis cases was $1.1 \pm 0.12$; for moderate periodontitis cases, $1.09 \pm 0.25$; and for severe periodontitis cases, $1.14 \pm 0.14$. ANOVA test values between the groups showed a statistical significance $(p<0.01)$ (Table 2).

\section{Discussion}

The correlation between periodontitis and chronic diseases is well documented. The reason well accepted is that the bacteria and their toxic products can enter the systemic circulation and exert its effects elsewhere in the body. It is also known that they can affect vascular endothelium in the coronary arteries. ${ }^{12,13}$ There are possibilities that the same damage can be caused in the kidney endothelium also. Sedý et al. gave evidence that in a dialyzed patient, periodontal pathogens can induce accelerated systemic and local bloodmediated response that can result in premature death. ${ }^{14}$

Sreeram et al. observed an increase in mean CRP, serum urea, and MDA and a decrease in eGFR uric acid and TAC in the patients with periodontitis and concluded that there is an increased risk for the development of CKD in the patients with periodontitis. ${ }^{15} \mathrm{~A}$ systematic review in 2013 showed that there is a positive association between periodontitis and CKD. There was also a beneficial effect periodontal therapy on eGFR. ${ }^{16}$

A study compared the bacterial accumulation in renal patients with periodontitis, and systemically healthy periodontitis cases showed no difference between the groups. In individuals with and without chronic renal failure, no significant differences were observed in most of the clinical periodontal parameters. ${ }^{17}$ Wahid et al. in 2014 showed that data from research articles published between 2000 and 2012 indicate a bidirectional relation between CKD and periodontal disease. ${ }^{18}$ In Barbudo-Selmi GR et al., there was no difference in serum levels of creatinine in dogs with mild, moderate and severe periodontitis. ${ }^{19}$ Also Taylor et al. reported even after extraction of all teeth from periodontitis patients, there was no change in urea levels. ${ }^{20}$

In lieu of the above controversy, this study was undertaken to evaluate the possible association between the periodontal status of the systemically healthy individuals and the SCR level to assess the role of periodontitis on renal function. In this study, we investigated the association between untreated periodontal diseases and renal function in terms of SCR in subjects previously diagnosed with periodontitis (test group) and periodontally healthy subjects (control group).

In most of the studies analyzing the relationship between periodontal status and renal functions/diseases, the study group included the patients with known renal dysfunction. But in this study, systemically healthy individuals with periodontitis were included which might be more appropriate to know if periodontal disease really has a systemic effect as compared to periodontally healthy controls.

Serum creatinine is by far the easiest diagnostic marker renal function and is readily available in laboratory settings. ${ }^{21}$ The SCR levels are greatly unaffected by typical diet. ${ }^{22,23}$ Since creatinine is derived from skeletal muscle, the levels may directly correlate with the body mass. ${ }^{24} \mathrm{~A}$ study conducted in athletes demonstrated a direct relationship between SCR concentration and BMI. ${ }^{25}$ One study demonstrated that only in a younger age group, BMI was associated with periodontal disease, whereas another study showed a direct relationship in adult, nonsmoking females but not in adult males or smoking females. ${ }^{26,27}$

Few studies have shown that low SCR concentrations may suggest low lean body mass, which may be associated with the incidence of type II diabetes. Also, between individuals with and without diabetes, lower levels of SCR were observed in the first group. ${ }^{28,29}$ Hence, on the recruitment of cases, BMI, systolic and diastolic blood pressure, and serum glucose (PP) were analyzed. 
Table 1: Comparison of serum creatinine values between the two groups

\begin{tabular}{|c|c|c|c|c|c|c|}
\hline \multirow[b]{2}{*}{ Parameters } & \multicolumn{2}{|c|}{ Group I } & \multicolumn{2}{|c|}{ Group II } & \multirow[b]{2}{*}{ Test value } & \multirow[b]{2}{*}{$p$ value } \\
\hline & Mean & $S D$ & Mean & $S D$ & & \\
\hline Age & 45.14 & 12.2 & 44.12 & 12.0 & - & - \\
\hline $\mathrm{BMI}$ & 26.20 & 8.4 & 25.82 & 10.2 & - & - \\
\hline Number of teeth & 28.09 & 2.22 & 23.42 & 2.32 & - & - \\
\hline PPD & 5.19 & 0.53 & 1.81 & 0.26 & 12.56 & 0.001 \\
\hline CAL & 5.51 & 0.53 & 1.81 & 0.26 & 12.00 & 0.001 \\
\hline Serum creatinine & 1.06 & 0.13 & 1.17 & 0.16 & 40.05 & 0.001 \\
\hline
\end{tabular}

$p$ value $<0.005$ shows statistical significance

Table 2: Comparison of serum creatinine values among mild, moderate, and severe periodontitis cases

\begin{tabular}{lll}
\hline & \multicolumn{2}{c}{ Serum creatinine } \\
\cline { 2 - 3 } Disease severity (CAL) & Mean & $S D$ \\
\hline $1-2 \mathrm{~mm}$ (mild) & 1.01 & 0.12 \\
$3-4 \mathrm{~mm}$ (moderate) & 1.09 & 0.25 \\
$\geq 5 \mathrm{~mm}$ (severe) & 1.14 & 0.14 \\
$p$ value & 0.01 & \\
\hline
\end{tabular}

$p$ value $<0.005$ shows statistical significance

Those with blood pressure variables $>130 / 90$, BMI $>25.0$, and postprandial glucose levels $>140 \mathrm{mg} / \mathrm{dL}$ were excluded from the study.

The results of this study show that the SCR value in Group I was $1.06 \pm 0.13$ and in Group II was $1.17 \pm 0.16$. This was statistically significant. This result suggests an inverse relationship between SCR concentrations and periodontal disease status.

In accordance with the study conducted by Brotto et al., ${ }^{30}$ kidney function markers (urea, creatinine, uric acid, and albumin contents) measured in the serum were measured in periodontally healthy cases and periodontitis controls. Between the test and control groups, no difference was found in the levels of markers. It was also proposed that periodontal diseases did not alter kidney function.

Similarly, Shimazaki Y et al. ${ }^{31}$ explored the periodontal status in Japanese middle-aged males with normal SCR levels and found a significant inverse association.

The exact mechanism linking serum concentrations of creatinine and periodontal disease is still unclear. Thus, SCR appears to be a less reliable tool to assess the relationship between kidney function and untreated periodontal disease. ${ }^{31}$

\section{ConcLusion}

This study shows an inverse relationship between the SCR levels and periodontal status. The causal relationship between periodontitis and low SCR could not be established. This inverse relationship might confound the analysis of the link between renal function and periodontal disease.

\section{Ethical Approval}

All the procedures performed in this study involving human participants were in accordance with the ethical standards of the institution and national research committee and with Declaration of Helsinki 1964, and its later amendments.

\section{Informed Consent}

Written informed consent was obtained from all the participants in this study.

\section{References}

1. American Academy of Periodontology. International workshop for a classification of periodontal disease and conditions. Ann Periodontol 1999;4(1):1-112. DOI: 10.1902/annals.1999.4.1.1.

2. Papapanou PN, Trevisan M. Periodontitis and atherosclerotic vascular disease, what we know and why it is important. J Am Dent Associat 2012;143(8):826-828. DOI: 10.14219/jada.archive.2012.0275.

3. Ide M, Papapanou PN. Epidemiology of association between maternal periodontal disease and adverse pregnancy outcomes- systematic review. J Clin Periodontol, 2013;40(suppl s14):S181-S194. DOI: 10.1902/ jop.2013.134009.

4. Preshaw PM, Alba AL, Herrera D, Jepsen S, Konstantinidis A, Makrilakis K, et al. Periodontitis and diabetes: a two-way relationship. Diabetologia 2012;55(1):21-31. DOI: 10.1007/s00125-0112342-y.

5. Anil S, Al Ghamdi HS. The impact of periodontal infections on systemic diseases. an update for medical practitioners. Saudi Med J 2006;27(6):767-776.

6. Bullon P, Morillo JM, Ramirez-Tortosa MC, Quiles JL, Newman HN, Battino M. Metabolic syndrome and periodontitis: is oxidative stress a common link. J Dent Res 2009;88(6):503-518. DOI: 10.1177/0022034509337479.

7. Harita N, Hayashi T, Sato KK, Nakamura Y, Yoneda T, Endo G, et al. Lower serum creatinine is a new risk factor of type 2 diabetes: the Kansai healthcare study. Diabetes Care 2009;32(3):424-426. DOI: 10.2337/dc08-1265.

8. Perrone RD, Madias NE, Levey AS. Serum creatinine as an index of renal function: new insights into old concepts. Clin Chem 1992;38(10): 1933-1953. DOI: 10.1093/clinchem/38.10.1933.

9. Joseph R, Krishnan R, Narayan V. Higher prevalence of periodontal disease among patients with predialytic renal disease. Braz J Oral Sci 2009;8:14-18.

10. Rahmati MA, Craig RG, Homel P, Kaysen GA, Levin NW. Serum markers of periodontal disease status and inflammation in hemodialysis patients. Am J Kidney Dis 2002;40(5):983-989. DOI: 10.1053/ ajkd.2002.36330.

11. Kshirsagar AV, Moss KL, Elter JR, Beck JD, Offenbacher S, Falk RJ. Periodontal disease is associated with renal insufficiency in the atherosclerosis risk in communities (ARIC) study. Am J Kidney Dis 2005;45(4):650-657. DOI: 10.1053/j.ajkd.2004.12.009.

12. Jansson L, Lavstedt S, Frithiof I, Theobald H. Relationship between oral health and mortality in cardiovascular diseases. J Clin Periodontol 2001;28(8):762-768. DOI: 10.1034/j.1600-051x.2001. 280807.x.

13. Tuominen R, Reunanen A, Paunio M, Paunio J, Aromaa A. Oral health indicators poorly predict coronary heart disease deaths. J Dent Res 2003;82(9):713-718. DOI: 10.1177/154405910308200911. 
14. Sedý J, Horká E, Foltán R, Spacková J, Dusková J. Mechanism of increased mortality in hemodialysed patients with periodontitis. Med Hypotheses 2010;74(2):374-376. DOI: 10.1016/j.mehy.2009.04.053.

15. Sreeram M, Suryakar AN, Dani NH, Kulkarni MB. Is periodontitis associated with decreased glomerular filtration rate, with oxidative stress as an important link? IOSR J Dent Med Sci (IOSR-JDMS) 2013;12(3):41-47. DOI: 10.9790/0853-1234147.

16. Chambrone L, Foz AM, Guglielmetti MR, Pannuti CM, Artese HP, Feres $\mathrm{M}$, et al. Periodontitis and chronic kidney disease: a systematic review of the association of diseases and the effect of periodontal treatment on estimated glomerular filtration rate. J Clin Periodontol 2013;40(5):443-456. DOI: 10.1111/jcpe.12067.

17. Yamalik N, Delilbasi L, Gulay H, Caglayan F, Haberal M, Caglayan G. The histological investigation of gingiva from patients with chronic renal failure, renal transplants, and periodontitis: a light and electron microscopic study. J Periodontol 1991;62(12):737-744. DOI: 10.1902/ jop.1991.62.12.737.

18. Wahid A, Chaudhry S, Ehsan A, Butt S, Ali Khan A. Bidirectional relationship between chronic kidney disease \& periodontal disease. Pak J Med Sci 2013;29(1):211-215. DOI: 10.12669/pjms.291.2926.

19. Barbudo-Selmi GR, Carvalho MB, Selmi AL, Selmi AL, Martins SEC. Periodontal disease characterization in dogs with normal renal function or chronic renal failure. Ciênc Rural 2004;34(1):113-118. DOI: 10.1590/S0103-84782004000100017.

20. Taylor BA, Tofler GH, Carey HMR, Morel-Kopp MC, Philcox S, Carter $T R$, et al. Full-mouth tooth extraction lowers systemic inflammatory and thrombotic markers of cardiovascular risk. J Dent Res 2006;85(1): 74-78. DOI: 10.1177/154405910608500113.

21. Wei F, Cheng S, Korin Y, Reed EF, Gjertson D, Ho C, et al. Serum creatinine detection by a conducting-polymer-based electrochemical sensor to identify allograft dysfunction. Anal Chem 2012;84(18):7933-7937. DOI: $10.1021 /$ ac3016888.

22. Marcotte L, Godwin M. Natural history of elevated creatinine levels. Can Fam Physician 2006;52(10):1264-1265.
23. Sato KK, Hayashi, Harita N, Koh H, Maeda I, Endo G, et al. Elevated white blood cell count worsens proteinuria but not estimated glomerular filtration rate: the Kansai healthcare study. Am J Nephrol 2011;34(4):324-329. DOI: 10.1159/000330845.

24. DeFronzo RA, Gunnarsson R, Bjo"rkman O, Olsson M, Wahren J. Effects of insulin on peripheral and splanchnic glucose metabolism in noninsulin-dependent (type II) diabetes mellitus. J Clin Invest 1985;76(1):149-155. DOI: 10.1172/JCI111938.

25. Banfi G, Del Fabbro M, Lippi G. Relation between serum creatinine and body mass index in elite athletes of different sport disciplines. Br J Sports Med 2006;40(8):675-678. DOI: 10.1136/bjsm.2006.026658.

26. Al-Zahrani MS, Bissada NF, Borawskit EA. Obesity and periodontal disease in young, middle-aged, and older adults. J Periodontol 2003;74(5):610-615. DOI: 10.1902/jop.2003.74.5.610.

27. Dalla Vecchia CF, Susin C, Rösing CK, Oppermann RV, Albandar JM. Overweight and obesity as risk indicators for periodontitis in adults. J Periodontol 2005;76(10):1721-1728. DOI: 10.1902/jop.2005.76. 10.1721.

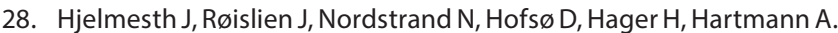
Low serum creatinine is associated with type 2 diabetes in morbidly obese women and men: A cross-sectional study. BMC Endocr Disord 2010;10(1):6. DOI: 10.1186/1472-6823-10-6.

29. Inaba M, Kurajoh M, Okuno S, Imanishi Y, Yamada S, Mori K, et al. Poor muscle quality rather than reduced lean body mass is responsible for the lower serum creatinine level in hemodialysis patients with diabetes mellitus. Clin Nephrol 2010;74(4):266-272.

30. Brotto RS, Vendramini RC, Brunetti IL, Marcantonio RAC, Ramos APP, Pepato MT. Lack of correlation between periodontitis and renal dysfunction in systemically healthy patients. Eur J Dent 2011;5(1):8-18. DOI: 10.1055/s-0039-1698853.

31. Shimazaki Y, Kushiyama M, Murakami M, Yamashita Y. Relationship between normal serum creatinine concentration and periodontal disease in japanese middle-aged males. J Periodontol 2013;84(1): 94-100. DOI: 10.1902/jop.2012.110528. 